\title{
Synthesis, characterization and concentration dependant antibacterial potentials of nickel oxide nanoparticles against Staphylococcus aureus and Escherichia coli
}

\author{
V. Gupta ${ }^{1, *}$, V. Kant ${ }^{2}$, A. Gupta ${ }^{3}$, M. Sharma ${ }^{1}$ \\ ${ }^{1}$ Department of Chemistry, University of Jammu, J\&K, India \\ ${ }^{2}$ Division of Pharmacology \& Toxicology, IVRI, Bareilly, UP, India \\ (Present address: Department of Veterinary Pharmacology \& Toxicology, LUVAS, Hisar) \\ ${ }^{3}$ Department of Physics, University of Jammu, J\&K, India \\ *vijayta1gupta@gmail.com
}

DOI 10.17586/2220-8054-2020-11-2-237-245

\begin{abstract}
Bacterial resistance to antibiotic treatment is a major emerging clinical and public health issue across the globe. Advancements in the field of metal oxide nanomaterials in the last few years have improved the potential of metal oxides in different applications. Metal oxides, of which, nickel oxide (NiO) is one, also possess antibacterial activities. This investigation was planned to synthesize NiO nanoparticles to study their antibacterial potential in comparison with bulk $\mathrm{NiO}$ and standard antibiotics at different concentrations. Synthesis and characterization of NiO nanoparticles was done by standard procedures. The antibacterial potentials of different compounds were determined at different concentrations against $S$. aureus and E. coli. The diameter of zone of inhibition showed that the antibacterial effect of NiO nanoparticles against $S$. aureus was better than $E$. coli at the same concentration. The concentration-dependent effect of NiO nanoparticles was observed from 0.125 to $128 \mu \mathrm{g} / \mathrm{ml}$. The effect of NiO nanoparticles was markedly better than bulk $\mathrm{NiO}$ at all concentrations. Tetracycline and gentamicin did not show effect below $1.0 \mu \mathrm{g} / \mathrm{ml}$ and $2.0 \mu \mathrm{g} / \mathrm{ml}$, respectively. The activity index and fold increase of $\mathrm{NiO}$ nanoparticles were both higher than 1 and positive, with respect to tetracycline, gentamicin and bulk $\mathrm{NiO}$ against $S$. aureus and E. coli at all the tested concentrations. In conclusion, the NiO nanoparticles seemed to be a more potent antibacterial agent than their bulk form, tetracycline and gentamicin, and in future, their applications may be extended in biomedical field and other areas to reduce microbial infections and incidences of antibacterial resistance.
\end{abstract}

Keywords: nickel oxide nanoparticles, S. aureus, E. coli, Antibacterial activity, activity index, fold increase.

Received: 20 March 2020

Revised: 3 April 2020

\section{Introduction}

The growth and proliferation of bacteria can occur fruitfully anywhere. Bacterial infections, due to both grampositive as well as gram-negative bacterial strains, are considered as serious health problems worldwide. Bacterial infectious diseases cause huge morbidity and mortality, thus, there is need to develop effective antimicrobial agents. Over the years, different infections resulting from society as well as hospital atmosphere have been controlled by the use of antibiotics [1]. Exposure of bacteria to several environmental variations such as temperature, osmolarity, radiation, toxins, and limited nutrition make them capable to survive in diverse environments by developing various approaches. Bacterial resistance to antibiotic treatment is emerging a major clinical and public health issue across the globe, which is also a serious concern for physician. Antimicrobial resistance is mainly due to indiscriminate use of antibiotic medications, lack of new strategies for antibacterial resistance development etc. [2]. This problem has added financial burden to the healthcare system. It is also predicted that antibacterial resistance will achieve worldwide epidemic proportions by 2050 and account for approximately 10 million casualties [3,4]. In view of its global importance, appropriate strategies and actions are needed from governmental sectors, industry, healthcare professions, farmers, society etc. Bacteria can develop resistance to treatments by different pathways, like decreased influx and increased efflux mechanisms, alteration in binding target sites, production of some enzymes etc. Development of more efficient antibacterial agents to overcome the problems of bacterial mutation, antibiotic resistance, outbreaks of pathogenic strains, etc. is demanded in the present era.

Different metals and metal oxides have been used as an antimicrobial agents for thousands of years. Indians have also used copper and silver to preserve food and disinfect water [5]. However, after the discovery of antibiotics in the twentieth century, their antimicrobial properties in a variety of medical applications have rapidly diminished. Recent basic and applied research on various metal oxides has led to their broad scale application in various areas such as catalysis, in semiconductors, sensors, controlled release of drugs and as antimicrobial agents. Advancements in the field of nanobiotechnology in the last few years have also led to the development of various metal oxide nanomaterials, which are emerging as one of the new antibacterial agents. Studies on the synthesis, characterization and applications 
of nanoparticles as an antimicrobial system is the latest area of interest in the biomedical and healthcare sectors. Nanoparticles are considered better antimicrobial agents than their bulk forms against drug-resistant pathogens due to size effect, doping effect, cost effective and stability, prolonged shelf-life etc. Recently, nanoparticles of many metal oxides like zinc oxide, copper oxide, iron oxide, cobalt oxide, cerium oxide etc. have shown various biological activities including antibacterial activity against Gram-positive and Gram-negative bacteria [6-9]. The bactericidal property by different metal oxide nanoparticles occurs by various mechanisms [10]. Additionally, nanoparticles of cobalt have shown better antibacterial efficacy than its bulk form against Staphylococcus aureus (S. aureus) and Escherichia coli (E. coli) [11]. It has also been reported that silver nanoparticles stabilized with neomycin-chitosan has enhanced antimicrobial activity relative to the neomycin-chitosan system and silver nanoparticles alone [12].

Nickel oxide (NiO), a P-type semiconductor transition metal oxide, in bulk and nano size has received significant attention due to its wide range of applications in different fields [13]. The nano NiO possesses significantly different catalytic, optical, electronic, and magnetic properties than its bulk form due to quantum size and surface effects $[14,15]$. Although, various investigations have documented the efficient applications and properties of NiO based materials, but the detailed studies on antimicrobial activity of $\mathrm{NiO}$ and its nano form are very limited and mostly lacking in comparison of antibacterial actions of $\mathrm{NiO}$ nanoparticles with respect to its bulk form as well as standard antibiotics. In view of this, the present investigation sought to prepare $\mathrm{NiO}$ nanoparticles to determine their antibacterial action against commonly present bacterial strains i.e. S. aureus and E. coli, and their comparison of antibacterial actions to bulk $\mathrm{NiO}$ and standard antibacterials (tetracycline and gentamicin) at different concentrations.

\section{Materials and method}

\subsection{Materials used}

The different chemicals of analytical grade were used for in this investigations. Nickel nitrate and sodium hydroxide were used for the synthesis of NiO nanoparticles and purchased from Sigma Aldrich, USA. Dimethyl sulfoxide (DMSO) was purchased from SRL. Tetracycline and gentamicin were procured from Sigma Aldrich, USA. The Muller-Hinton Agar (MHA), Muller-Hinton Broth (MHB) and nutrient broth (NB) were purchased from Hi-media, Mumbai, India and used for antibacterial studies. The S. aureus (MTCC 1430) and E. coli (MTCC 2127) gifted from the Department of Biotechnology, University of Jammu were revived using the nutrient broth (NB) and used two bacterial strains in this study.

\subsection{Synthesis of $\mathrm{NiO}$ nanoparticles}

Aqueous solution of $0.25 \mathrm{M}$ nickel nitrate and $1.25 \mathrm{M}$ sodium hydroxide with constant stirring at $55{ }^{\circ} \mathrm{C}$ were reacted for the synthesis of $\mathrm{NiO}$ nanoparticles. The complete mixture was magnetically stirred for $2 \mathrm{~h}$ at $\mathrm{pH} 12$, forming a green precipitate of nickel hydroxide which was centrifuged, filtered and washed. Thereafter, they were calcined at $600{ }^{\circ} \mathrm{C}$ for $3 \mathrm{~h}$ to obtain $\mathrm{NiO}$ nanoparticles. The synthesized $\mathrm{NiO}$ nanoparticles at different concentrations were dispersed in DMSO by employing ultrasonication for further studies. There was no addition of stabilizer during any step in order to avoid its effects on the surface property of the nanoparticle as well as chemical contamination.

\subsection{Characterization of $\mathrm{NiO}$ nanoparticles}

The synthesized nanoparticles were characterized by using various techniques like particle size analyzer (PSA), transmission electron microscopy (TEM) and scanning electron microscopy (SEM). The particle size distribution (PSD) analysis of the synthesized nanoparticles was done by Malvern Instruments Zetasizer Nano-ZS instrument. The transmission electron microscope (Hitachi H-7500) was used to evaluate the size and morphology of nanoparticles. The surface morphology of the particles was observed by a scanning electron microscope (SEM-EDS) using SEM (JEOL JSM - 6390LV).

\subsection{Assessment of antibacterial activity}

2.4.1. Determination of zone of inhibition by well-diffusion method. Different concentrations of tetracycline, gentamicin, bulk $\mathrm{NiO}$ and synthesized $\mathrm{NiO}$ nanoparticles were used to evaluate their antibacterial potentials against the gram-positive i.e. S. aureus and gram-negative i.e. E. coli bacterial strains. The antibacterial activity was determined on Muller-Hinton agar by the agar well diffusion method [16]. The agar used for the study was seeded with overnight cultures of different bacterial strains $\left(10^{8} \mathrm{cfu} / \mathrm{ml}\right)$ and then poured $(12 \mathrm{ml})$ in petri plates. Five $6 \mathrm{~mm}$ wells of diameter were punched into the agar plates for testing antimicrobial activity of nanoparticles and other compounds. Prepared wells were also sealed with one drop of melted agar $(0.8 \%$ agar $)$ to prevent the leakage of nanoparticles and other compounds from the bottom of the wells. Using a micropipette, different dilutions of $\mathrm{NiO}$ nanoparticles, bulk $\mathrm{NiO}$ and antibiotics were poured onto each of five wells on all plates. After overnight incubation at $37^{\circ} \mathrm{C}$, the different 
diameters of zone of inhibition were measured to quantify the antibacterial activity. In this study, DMSO was used as negative control, and tetracycline and gentamicin were used as positive control to compare the efficacy of the nanoparticles. The same experiment for all the dilutions was conducted in triplicate. The activity index and fold increase for the comparison of antibacterial potentials of $\mathrm{NiO}$ nanoparticles with bulk $\mathrm{NiO}$ and standard antibiotics was also determined by using values of zone of inhibition.

2.4.2. Activity index for NiO nanoparticles. The activity index was calculated by comparing the resultant zones of inhibition of $\mathrm{NiO}$ nanoparticles with the standard antibiotic or bulk $\mathrm{NiO}$ by using the following formula:

$$
\text { Activity Index }(\mathrm{AI})=\frac{\text { Inhibition zone of the } \mathrm{NiO} \text { nanoparticles }}{\text { Inhibition zone of the bulk } \mathrm{NiO} \text { or standard antibiotic }}
$$

2.4.3. Fold increase for $\mathrm{NiO}$ nanoparticles. Fold increase was also determined by comparing the resultant zones of inhibition of $\mathrm{NiO}$ nanoparticles with the standard antibiotic or bulk NiO. The fold increase was calculated by using the following equation:

$$
\text { Fold increase }(\%)=\frac{b-a}{a} \cdot 100,
$$

where $a$ and $b$ refer to the inhibition zones of antibiotic/ bulk NiO and $\mathrm{NiO}$ nanoparticles, respectively.

\section{Results and discussion}

The PSD of NiO nanoparticles is shown in Fig. 1A and it showed the overall z-average size of $178.6 \mathrm{~nm}$ with a polydispersity index of 0.239 . This signified that the particle size distribution consisted of a single size mode devoid of aggregates. The TEM (Fig. 1B) and SEM (Fig. 1C) micrographs of NiO nanoparticles showed that the synthesized NiO nanoparticles have the average size of $40-55 \mathrm{~nm}$ and almost spherical shape. The SEM micrograph also demonstrated that the majority of the particles displayed little aggregation.
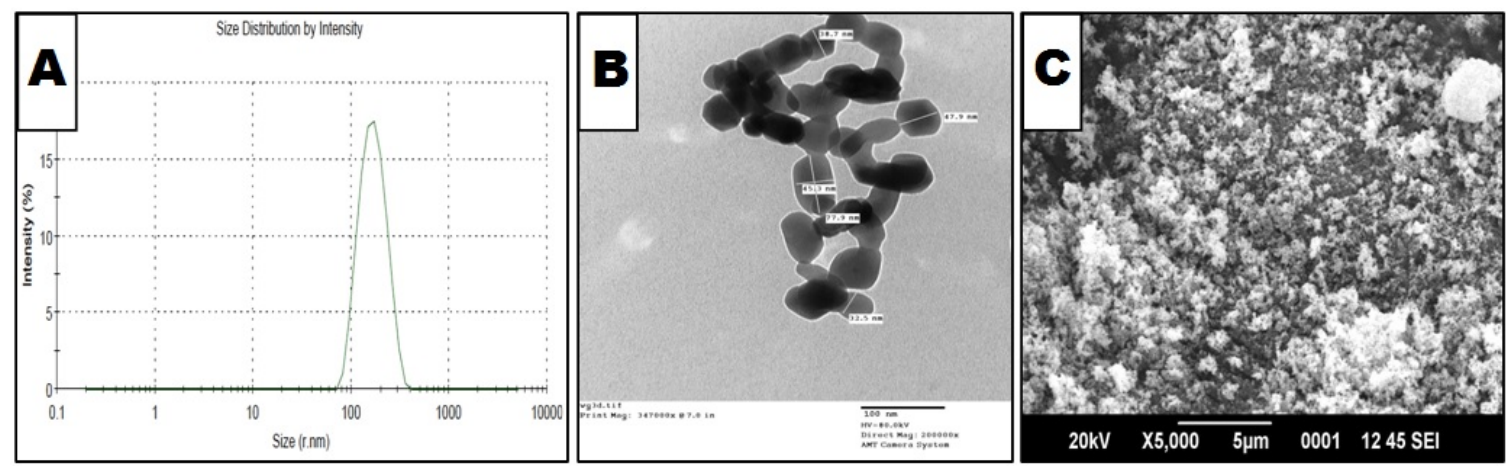

FIG. 1. (A) The particle size distribution (PSD) of NiO nanoparticles. Micrograph of TEM (B) and SEM (C) of $\mathrm{NiO}$ nanoparticles

Images of bacterial culture plates of present study evidently showed that tetracycline, gentamicin, bulk $\mathrm{NiO}$ and $\mathrm{NiO}$ nanoparticles produced zones of inhibition against $S$. aureus and E. coli in concentration dependent manners (Fig. 2). The mean diameters of zones of inhibition for different tested compounds at different concentrations are presented in Table 1. It has been previously reported that the inhibition of bacterial growth increases with an increase in concentration of nanoparticles [17]. Earlier, different nanoparticles have been studied for antimicrobial activities against human pathogenic bacteria such as $S$. aureus and E. coli $[18,19]$. The synthesized NiO nanoparticles produced larger zone of inhibition against $S$. aureus in comparison to $E$. coli at the same concentration. It was revealed that $\mathrm{NiO}$ nanoparticles have stronger action against $S$. aureus than $E$. coli. These results are in agreement with the earlier studies in which $S$. aureus were more sensitive than $E$. coli to antibacterial actions of Ni nanoparticles [20]. In recent years, also, few studies have shown the antimicrobial actions of $\mathrm{NiO}$ nanoparticles prepared by different methods. Khalil et al [21] biologically synthesized $\mathrm{NiO}$ nanoparticles by using aqueous leaf extracts of Sageretia thea, and observed their antimicrobial properties by in vitro assays. Their study also revealed that the antibacterial activities of $\mathrm{NiO}$ nanoparticles were enhanced after UV illumination and E. coli as well as B. subtilis were the most susceptible strains. Srihasam et al., [22] produced NiO nanoparticles using Stevia leaf broth, which showed the antimicrobial actions strongly against gram-negative bacteria. The synthesized nanoparticles in their study ranged from 20 to $50 \mathrm{~nm}$ and were spherical in shape. Helan et al [23] prepared the $\mathrm{NiO}$ nanoparticles with the help of phytoconstituents present in the neem leaf and observed their antibacterial activity, which was concentration-dependent. In their study, 

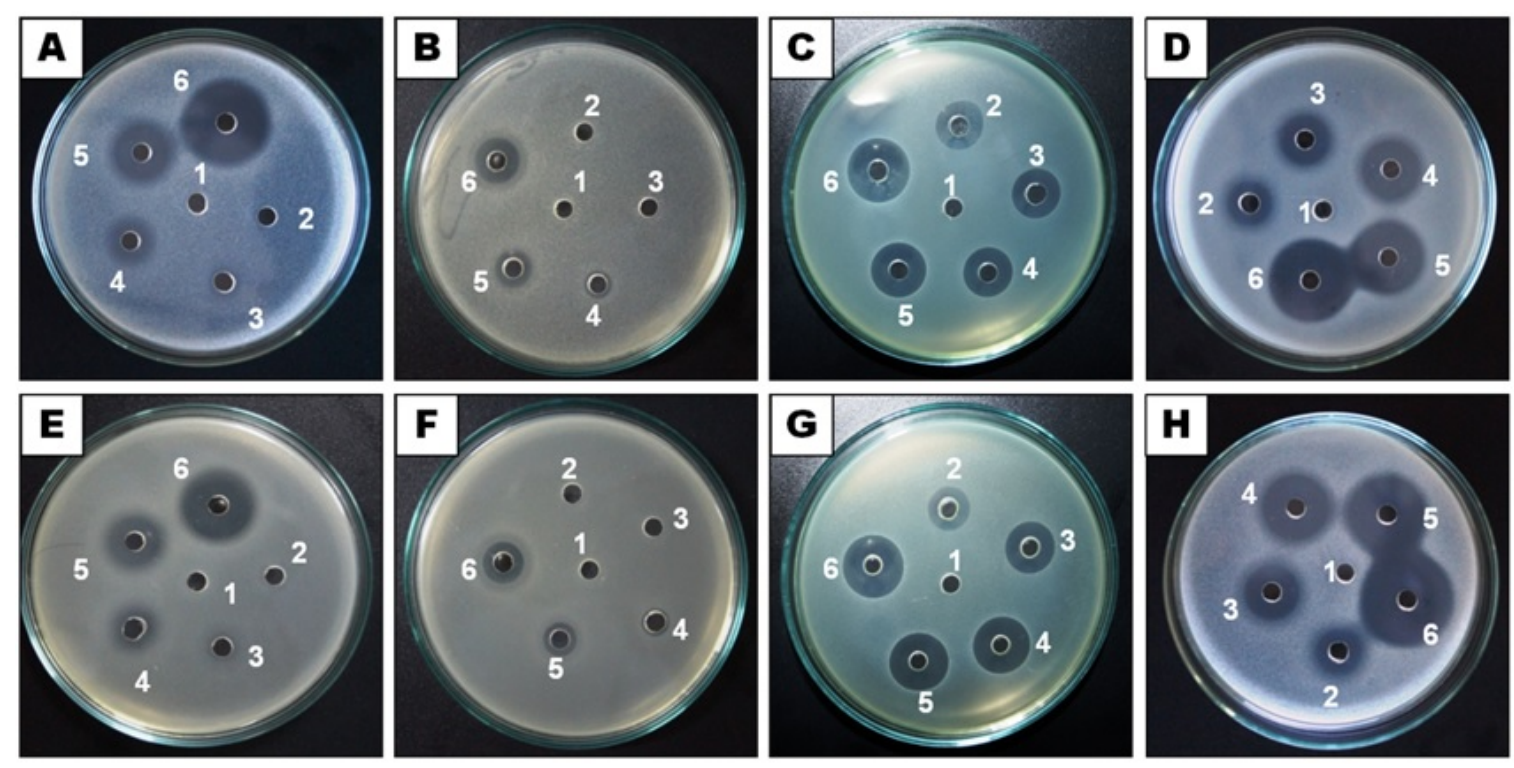

FIG. 2. Zone of inhibitions of tetracycline (A,E), gentamicin $(\mathrm{B}, \mathrm{F})$, bulk $\mathrm{NiO}(\mathrm{C}, \mathrm{G})$ and $\mathrm{NiO}$ nanoparticles $(\mathrm{D}, \mathrm{H})$ against $S$. aureus $(\mathrm{A}-\mathrm{D})$ and $E$. coli as $(\mathrm{E}-\mathrm{H})$ at different concentrations i.e. (1) $0.00 \mu \mathrm{g} / \mathrm{ml}$, (2) $0.125 \mu \mathrm{g} / \mathrm{ml}$, (3) $0.5 \mu \mathrm{g} / \mathrm{ml}$, (4) $2.0 \mu \mathrm{g} / \mathrm{ml}$, (5) $16.0 \mu \mathrm{g} / \mathrm{ml}$ and (6) $128 \mu \mathrm{g} / \mathrm{ml}$

morphological analysis revealed oblong shape and $12 \mathrm{~nm}$ size of nanoparticles. Abbasi et al [24] also synthesized $\mathrm{NiO}$ nanoparticles by an environmentally-benign synthetic method using Geranium wallichianum as reducing and capping agent. The $\mathrm{NiO}$ nanoparticles in their study were of $21 \mathrm{~nm}$ size and nanoparticles showed showed antibacterial potential against different bacterial strains at different concentrations (700-21.875 $\mu \mathrm{g} / \mathrm{ml})$. In their study, the $B$. subtilis (MIC: $21.875 \mu \mathrm{g} / \mathrm{ml}$ ) was the most susceptible organism, and $K$. pneumonia (MIC: $175 \mu \mathrm{g} / \mathrm{ml}$ ) as well as $P$. aeruginosa (MIC: $175 \mu \mathrm{g} / \mathrm{ml}$ ) were the least susceptible bacterial strains with respect to the action of NiO nanoparticles. Bhat et al [25] synthesized face-centered cubic structure of $\mathrm{NiO}$ nanoparticles with $30 \mathrm{~nm}$ average size by co-precipitation method. In their study, K. pneumonia and B. subtilis showed maximum zone of inhibition (15 mm) at $40 \mathrm{mg} / \mathrm{ml}$ concentration, and minimum inhibitory concentration $62.5 \mu \mathrm{g} / \mathrm{ml}$. In our present study, the antibacterial actions of synthesized $\mathrm{NiO}$ nanoparticles increased with an increase in concentration, and this concentration dependent action was observed only from 0.125 to $128 \mu \mathrm{g} / \mathrm{ml}$. It was observed in this study that the action of the nanoparticles decreased when the concentration of nanoparticles increased beyond $128 \mu \mathrm{g} / \mathrm{ml}$. This decreased action at higher concentrations was postulated to be due to the agglomeration of nanoparticles at higher concentrations. Some previous studies have also explained in their findings that nanoparticles possess some optimum concentration at which higher effects are noticed in comparison to more or less concentration [26]. Thus, the optimum concentration for NiO nanoparticles in the present study was $128 \mu \mathrm{g} / \mathrm{ml}$. Standard antibacterials i.e. tetracycline and gentamicin did not show zones of inhibition at lower concentrations i.e. below $1.0 \mu \mathrm{g} / \mathrm{ml}$ for tetracycline and below $2.0 \mu \mathrm{g} / \mathrm{ml}$ for gentamicin (Table 1) and seemed ineffective at lower concentrations. On the other hand, the bulk $\mathrm{NiO}$ and $\mathrm{NiO}$ nanoparticles used in this study were effective below these concentrations (Tables 1). It suggested that the range of inhibitory concentration for bulk and nano $\mathrm{NiO}$ was broader with respect to both tetracycline and gentamicin. The antibacterial effects of nano form of $\mathrm{NiO}$ was observed markedly better than bulk form at all tested concentrations of present study. Hence, $\mathrm{NiO}$ nanoparticles can provide antibacterial action for longer duration with less frequency of applications and may be considered as a substitute for tetracycline, gentamicin and bulk $\mathrm{NiO}$ in different fields in view of to diminish the occurrence of bacterial resistance.

The size, morphology and concentration of nanoparticles significantly influence their physical and chemical properties, which affect the degree of growth and survival of bacteria. Different previous studies have revealed that metal oxide nanoparticles between 1 and $100 \mathrm{~nm}$ size with different shapes are promising antimicrobial agents against infectious diseases [27]. The TEM micrograph in present study showed average size of 40-55 nm and spherical shape of synthesized $\mathrm{NiO}$ nanoparticles. So, nanoparticles synthesized in this study could be considered promising antimicrobial agents. The metal oxide nanoparticles induce bacterial toxicity through various mechanisms of actions like, oxidative stress, lipid peroxidation, cell membrane lysis, enzyme inhibition, proteolysis etc. [28]. The overall charge of the bacterial cell at physiological $\mathrm{pH}$ is negative due to the dissociation of excess carboxylic groups at the cell surface [29]. Since $\mathrm{NiO}$ has a positive surface charge, so, they became electrostatically bound to the negative cell surface, 
TABLE 1. Zone of inhibition for tetracycline, gentamicin, bulk NiO and NiO nanoparticles (NPs) against $S$. aureus and E. coli at different concentrations

\begin{tabular}{|c|c|c|c|c|c|c|c|c|}
\hline \multirow{2}{*}{$\begin{array}{c}\text { Conc. } \\
(\mu \mathrm{g} / \mathrm{ml})\end{array}$} & \multicolumn{2}{|c|}{ Zone of inhibition $(\mathrm{mm})$ against $S$. aureus } & \multicolumn{3}{c|}{ Zone of inhibition (mm) against $E$. coli } \\
\cline { 2 - 9 } & Tetracycline & Gentamicin & Bulk NiO & NiO NPs & Tetracycline & Gentamicin & Bulk NiO & NiO NPs \\
\hline 128.0 & 22.17 & 15.67 & 18.08 & 25.17 & 17.58 & 12.33 & 15.33 & 22.08 \\
\hline 64.0 & 19.17 & 13.75 & 17.00 & 22.83 & 16.00 & 11.17 & 14.25 & 21.33 \\
\hline 32.0 & 16.50 & 12.25 & 16.25 & 21.00 & 14.00 & 10.50 & 13.42 & 20.92 \\
\hline 16.0 & 13.08 & 10.50 & 15.17 & 19.50 & 11.83 & 8.75 & 12.42 & 18.58 \\
\hline 8.0 & 11.50 & 9.00 & 14.42 & 18.50 & 9.50 & 7.75 & 11.17 & 17.50 \\
\hline 4.0 & 8.83 & 7.42 & 12.00 & 17.67 & 8.00 & 7.08 & 10.67 & 16.33 \\
\hline 2.0 & 7.50 & 7.08 & 11.25 & 16.00 & 7.25 & 7.00 & 10.25 & 14.08 \\
\hline 1.0 & 7.25 & - & 10.58 & 13.50 & 7.08 & - & 9.42 & 12.58 \\
\hline 0.5 & - & - & 9.50 & 13.17 & - & - & 8.67 & 12.08 \\
\hline 0.25 & - & - & 9.00 & 11.00 & - & - & 8.25 & 10.00 \\
\hline 0.125 & - & - & 8.50 & 9.83 & - & - & 7.58 & 8.83 \\
\hline
\end{tabular}

which hinder the cellular activity. Penetration of $\mathrm{NiO}$ into the cell and its toxicity made the cell inactive and dead followed by lysis [30]. The penetration of $\mathrm{NiO}$ nanoparticles in bacteria through cell membrane leads to generation of reactive oxygen species (ROS), which leads to damage of cell components [31,32]. The antibacterial potential of the nanoparticles is mainly governed by the size, shape, dosage, stability, morphology, and treatment time [33]. In the present study, the smaller size of $\mathrm{NiO}$ nanoparticles was thought to be responsible for better antibacterial actions than its bulk form, as smaller size usually enhancedby the dispersibility and penetration into the intracellular matrix and interference with intracellular $\mathrm{Ca}^{2+}$ absorption leading to cell damage [22]. Attachment of the nickel ions released from the $\mathrm{NiO}$ nanoparticles to the cell membrane of the microbes initiate electrostatic interactions, wherein it interferes with cellular physiology leading to their disruption [34]. Further, these damaged cell membranes are more susceptible to further interactions, which lead to more penetration of $\mathrm{NiO}$ nanoparticles and leakage of the intracellular organelles [22]. These sequential steps augment the antimicrobial action of the nanoparticles. Additionally, the interactions of penetrated $\mathrm{NiO}$ nanoparticles generate the ROS, which has a significant tendency in interfering the microbial electron transport chain, damaging DNA by breaking the phosphate and hydrogen bonds, denaturing the protein by alteration of the tertiary structure, and damaging the mitochondria by oxidative stress [22,35]. The soluble nickel compounds attack the bacterial cell membrane from outside, whereas nanoparticles (metal/metal oxide) easily get entry through bacterial cell membrane and leading to the death of bacterial cell [36-38]. The schematically possible hypothetical mechanisms of $\mathrm{NiO}$ nanoparticles for the antibacterial actions are shown in Fig. 3. So, the direct contact of $\mathrm{NiO}$ nanoparticles may be responsible for damaging the cell membrane followed by cell lysis in present study. It has been observed that metal oxide nanoparticles do not generate bacterial resistance and are safe potential antimicrobial alternatives for clinical applications [39,40]. Most of the nanoparticles also did not inactivate or lose their properties when exposed to sterilization by different ways, like high temperature, gamma irradiation or plasma treatment etc. [41]. The various advantages and unique properties of nanoparticles have led to the incorporation of nano forms of oxides of silver, copper, titanium, zinc, iron etc. into the medical field has emerged as an alternative to new antimicrobial agents in recent years $[42,43]$. Further, NiO nanoparticles in comparison to it bulk form undergo marked transformations, which induce significant changes in their structural and physico-chemical properties, which in turn affects its better action.

Consideration of an antimicrobial agent as better than others can be done after the comparison its potential with some standard antimicrobials and its other forms. The calculation of activity index (AI) by using the values of zone of inhibition is considered one of the standard approaches for the comparison of antibacterial potentials of different compounds [44]. The testing drug/compound will be considered better against particular bacteria if it possess value of $\mathrm{AI}$ more than one. In the present investigation, the $\mathrm{AI}$ for $\mathrm{NiO}$ nanoparticles with respect to tetracycline, gentamicin and bulk NiO against $S$. aureus and E. coli was calculated at various concentrations, and the values are presented in Table 2. The $\mathrm{AI}$ of $\mathrm{NiO}$ nanoparticles with respect to tetracycline, gentamicin and bulk $\mathrm{NiO}$ against $S$. aureus and E. coli were found higher than 1 at all compared concentrations. These values also revealed that the AI of NiO nanoparticles against $S$. aureus and $E$. coli was higher for gentamicin in comparison to tetracycline and bulk $\mathrm{NiO}$ at the same concentration. Another method for the comparative studies of different antimicrobials is calculation of 


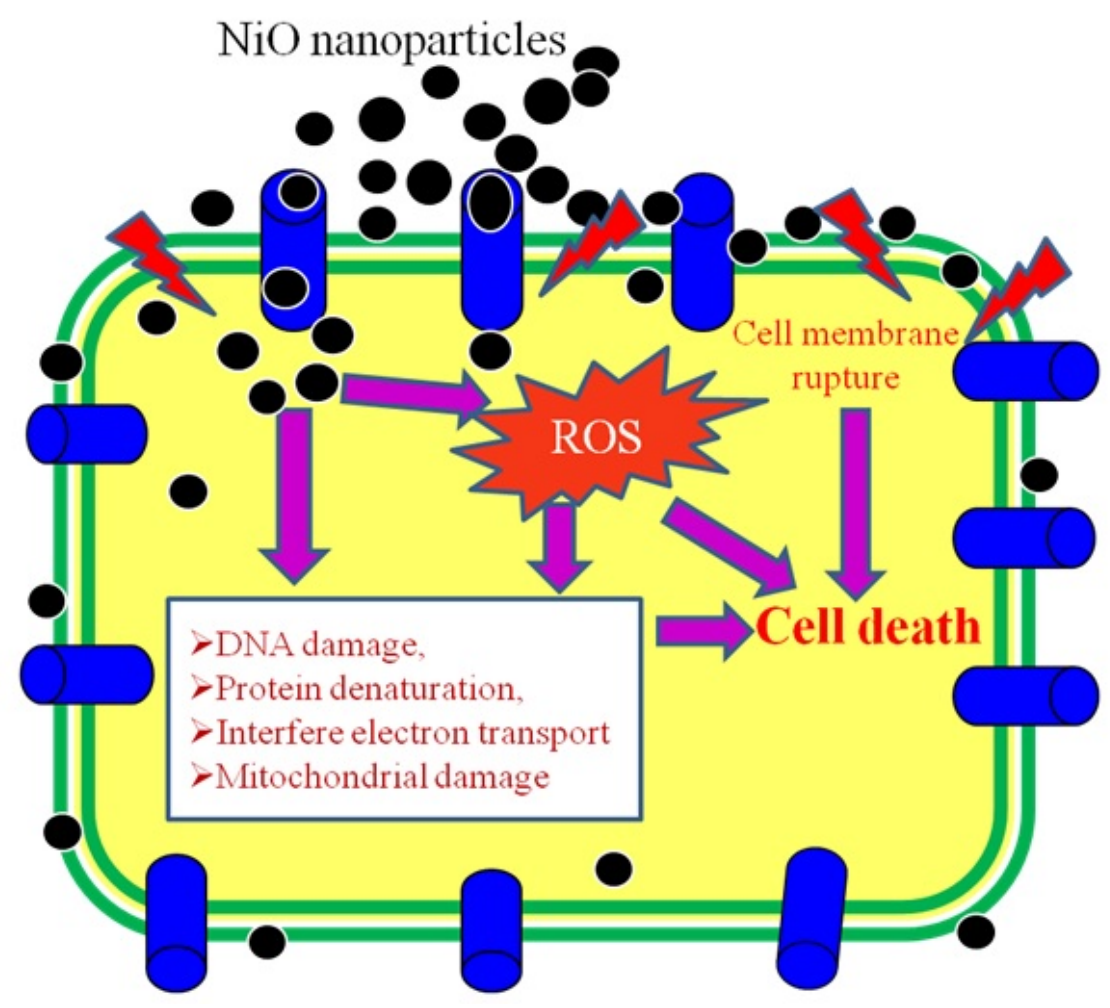

FIG. 3. The schematically possible hypothetical mechanisms of action of NiO nanoparticles for antibacterial activity

TABLE 2. Activity index of $\mathrm{NiO}$ nanoparticles with respect to tetracycline, gentamicin and bulk $\mathrm{NiO}$ against $S$. aureus and $E$. coli at different concentrations

\begin{tabular}{|c|c|c|c|c|c|c|}
\hline $\begin{array}{c}\text { Conc. } \\
(\mu \mathrm{g} / \mathrm{ml})\end{array}$ & $\begin{array}{c}\text { Activity Index w.r.t. } \\
\text { Tetracycline }\end{array}$ & \multicolumn{2}{|c|}{$\begin{array}{c}\text { Activity Index w.r.t. } \\
\text { Gentamicin }\end{array}$} & \multicolumn{2}{|c|}{$\begin{array}{c}\text { Activity Index w.r.t. } \\
\text { bulk NiO }\end{array}$} \\
\cline { 2 - 7 } & S. aureus & E. coli & S. aureus & E. coli & S. aureus & E. coli \\
\hline 128.0 & 1.14 & 1.26 & 1.61 & 1.79 & 1.39 & 1.44 \\
\hline 64.0 & 1.19 & 1.33 & 1.66 & 1.91 & 1.34 & 1.50 \\
\hline 32.0 & 1.27 & 1.49 & 1.71 & 1.99 & 1.29 & 1.56 \\
\hline 16.0 & 1.49 & 1.57 & 1.86 & 2.12 & 1.29 & 1.50 \\
\hline 8.0 & 1.61 & 1.84 & 2.06 & 2.26 & 1.28 & 1.57 \\
\hline 4.0 & 2.00 & 2.04 & 2.38 & 2.31 & 1.47 & 1.53 \\
\hline 2.0 & 2.13 & 1.94 & 2.26 & 2.01 & 1.42 & 1.37 \\
\hline 1.0 & 1.86 & 1.78 & - & - & 1.28 & 1.34 \\
\hline 0.5 & - & - & - & - & 1.39 & 1.39 \\
\hline 0.25 & - & - & - & - & 1.22 & 1.21 \\
\hline 0.125 & - & - & - & - & 1.16 & 1.16 \\
\hline
\end{tabular}


fold increase $(\%)$. This method represents the relative effect of tested compound in contrast to any standard antibiotic/drug/other compound and the positive value represents the better actions of tested compound. Conversely, the negative value of fold increase indicates that the tested compound is less effective against particular bacteria than standard antibiotic/drug/other compound at the same concentration. In our study, the values of fold increase (\%) for $\mathrm{NiO}$ nanoparticles with respect to tetracycline, gentamicin and bulk $\mathrm{NiO}$ against $S$. aureus and E. coli at different concentrations are presented in Table 3. The positive values of fold increase of $\mathrm{NiO}$ nanoparticles w.r.t. tetracycline, gentamicin and bulk $\mathrm{NiO}$ against $S$. aureus and E. coli were evident at all the concentrations in present study (Table 3).

It is well known phrase in biomedical sciences that the prevention is better than cure, so applying/coating of $\mathrm{NiO}$ nanoparticles on large active surface area, on cellulose bandages, uniforms, bed linen, medical equipment etc. may be useful preventive measures to control bacterial/microbial infections and will make a considerable input in reducing bacterial contamination, mortality, treatment of costs etc. In recent years, applications of nanotechnology in the biomedical field have given many beneficial results. In the biomedical field, various devices coated with antimicrobial nanomaterials such as heart valves, catheters, and dental implants have been used and in these devices there is delay or inhibition in the adhesion and growth of bacteria such as Streptococcus mutans, S. epidermis, and E. coli. [45]. The application of nanoparticles of different metals and their oxides like zinc, silver, copper or titanium, etc. has increased because of their bactericidal activity against both Gram-positive and Gram-negative bacterial strains. Silver nanoparticles are commonly and widely employed for different purposes like bactericides in catheters, burn wound care, and in the dental practice [46]. But, there are some issues related to the biological safety of silver nanoparticles and pigmentation effect of silver nanoparticles on teeth $[47,48]$. $\mathrm{NiO}$ is cheaper than silver and $\mathrm{NiO}$ nanoparticles may replace the silver nanoparticles in the coming years in various application. Additionally, metals oxide nanoparticles are considered better antimicrobial pharmaceuticals due to their durability, high stability, and low mammalian cell toxicity in comparison to organic nanoparticles [49]. The promising antimicrobial actions shown by different metals oxide nanoparticles, including $\mathrm{NiO}$ nanoparticles, could have a several therapeutic applications in biomedical field and their use can also be extended to food industry, water purification, textile industry, paint industry, sewage treatments, etc.

TABLE 3. Fold increase (\%) of $\mathrm{NiO}$ nanoparticles with respect to (w.r.t.) tetracycline, gentamicin and bulk $\mathrm{NiO}$ against $S$. aureus and $E$. coli at different concentrations

\begin{tabular}{|c|c|c|c|c|c|c|}
\hline $\begin{array}{c}\text { Conc. } \\
(\mu \mathrm{g} / \mathrm{ml})\end{array}$ & \multicolumn{2}{|c|}{$\begin{array}{c}\text { Fold increase (\%) w.r.t. } \\
\text { Tetracycline }\end{array}$} & \multicolumn{2}{|c|}{$\begin{array}{c}\text { Fold increase (\%) w.r.t. } \\
\text { Gentamicin }\end{array}$} & \multicolumn{2}{c|}{$\begin{array}{c}\text { Fold increase (\%) w.r.t. } \\
\text { bulk NiO }\end{array}$} \\
\cline { 2 - 7 } & S. aureus & E. coli & S. aureus & E. coli & S. aureus & E. coli \\
\hline 128.0 & 13.53 & 25.59 & 60.64 & 79.05 & 39.17 & 44.02 \\
\hline 64.0 & 19.13 & 33.33 & 66.06 & 91.04 & 34.31 & 49.71 \\
\hline 32.0 & 27.27 & 49.40 & 71.43 & 99.21 & 29.23 & 55.90 \\
\hline 16.0 & 49.04 & 57.04 & 85.71 & 112.38 & 28.57 & 49.66 \\
\hline 8.0 & 60.87 & 84.21 & 105.56 & 125.81 & 28.32 & 56.72 \\
\hline 4.0 & 100.00 & 104.17 & 138.20 & 130.59 & 47.22 & 53.13 \\
\hline 2.0 & 113.33 & 94.25 & 125.88 & 101.19 & 42.22 & 37.40 \\
\hline 1.0 & 86.21 & 77.65 & - & - & 27.56 & 33.63 \\
\hline 0.5 & - & - & - & - & 38.60 & 39.42 \\
\hline 0.25 & - & - & - & - & 22.22 & 21.21 \\
\hline 0.125 & - & - & - & - & 15.69 & 16.48 \\
\hline
\end{tabular}

\section{Conclusions}

In conclusion, the $\mathrm{NiO}$ nanoparticles were better antibacterial agents than their bulk form and they also seemed better than the standard antibiotics tetracycline and gentamicin, particularly at low concentrations, against both gram positive $(S$. aureus) and gram negative $(E$. coli) bacteria. In future, the strong antibacterial potentials of NiO nanoparticles may be extended its applications in different fields. 


\section{Acknowledgements}

The authors are thankful to Department of Chemistry and Department of Biotechnology, University of Jammu, for providing necessary facilities and support for conducting present study. The authors also acknowledge the support of SAIF STIC (Kochi), SAIF Chandigarh, CIL Chandigarh for providing the facilities for characterization.

\section{References}

[1] Hawkey P.M. The growing burden of antimicrobial resistance. J. Antimicrob. Chemother., 2008, 62, P. i1-i9.

[2] Livermore D.M. The 2018 Garrod lecture: Preparing for the black swans of resistance. J. Antimicrob. Chemother., 2018, 73, P. $2907-2915$.

[3] Sugden R., Kelly R., Davies S. Combatting antimicrobial resistance globally. Nat. Microbiol., 2016, 1, P. 16187.

[4] O’Neill J. Antimicrobial Resistance: Tackling a Crisis for the Health and Wealth of Nations. Rev. Antimicrob. Re., 2014.

[5] Galib M., Barve M., Mashru C, Jagtap B.J., Patgiri P.K., Prajapati. Therapeutic potentials of metals in ancient India: A review through Charaka Samhita. J. Ayurveda Integr. Med., 2011, 2, P. 55.

[6] Azam A., Ahmed A.S., Oves M., Khan M.S., Habib S.S., Adnan Memic. Antimicrobial activity of metal oxide nanoparticles against Grampositive and Gram-negative bacteria: a comparative study. Int. J. Nanomed., 2012, 7, P. 6003-6009.

[7] Bhushan M., Kumar Y, Periyasamy L., Viswanath A.K. Antibacterial applications of $\alpha-\mathrm{Fe}_{2} \mathrm{O}_{3} / \mathrm{Co}_{3} \mathrm{O}_{4}$ nanocomposites and study of their structural, optical, magnetic and cytotoxic characteristics. App. Nanosci., 2018, 8, P. 137-153.

[8] Ebadi M., Zolfaghari M.R., Aghaei S.S., Zargar M., Shafiei M., Zahiri H.S., Noghabi K.A. A bio-inspired strategy for the synthesis of zinc oxide nanoparticles ( $\mathrm{ZnO}$ NPs) using the cell extract of cyanobacterium Nostoc sp. EA03: from biological function to toxicity evaluation. RSC Adv., 2019, 9, P. 23508.

[9] Khadar Y.A.S., Balamurugan A., Devarajan V.P., Subramanian R., Kumar S.D. Synthesis, characterization and antibacterial activity of cobalt doped cerium oxide $\left(\mathrm{CeO}_{2}\right.$ :Co) nanoparticles by using hydrothermal method. J. Mater. Res. Technol., 2019 , 8(1), P. $267-274$

[10] Parham S., Wicaksono D.H.B., Bagherbaigi S., Lee S.L., Nur H. Antimicrobial treatment of different metal oxide nanoparticles: a critical review. J. Chin. Chem. Soc., 2016, 63, P. 385-393.

[11] Gupta V., Kant V., Sharma A.K., Sharma M. Comparative assessment of antibacterial efficacy for cobalt nanoparticles, bulk cobalt and standard antibiotics: A concentration dependant study. Nanosyst. Phys. Chem. Math., 2020, 11(1), P. 78-85.

[12] Preethika R.K., Ramya R., Ganesan M., Nagaraj S., Pandian K. Synthesis and characterization of neomycin functionalized chitosan stabilized silver nanoparticles and study its antimicrobial activity. Nanosyst. Phys. Chem. Math., 2016, 7(4), P. 759-764.

[13] Deraz N.M., Selim M.M., Ramadan M. Processing and properties of nanocrystalline Ni and NiO catalysts. Mater. Chem. Phys., 2009, 113, P. 269-275.

[14] Meyer M., Albrecht-Gary A.M., Dietrich-Buchecker C.O., Sauvage J.P. Dicopper(I) trefoil knots: Topological and structural effects on the demetalation rates and mechanism. J. Am. Chem. Soc., 1997, 119, P. 4599-4607.

[15] Li Y.G., Shi D.H., Zhu H.L., Yan H., Ng S.W. Transition metal complexes (M=Cu, Ni and Mn) of Schiff-base ligands: syntheses, crystal structures, and inhibitory bioactivities against urease and xanthine oxidase. Inorg. Chim. Acta., 2007, 360(9), P. $2881-2889$.

[16] Perez C., Pauli M., Bazerque P. An antibiotic assay by agar-well diffusion method. Acta Biol. Med. Exp., 1990, 15, P. $113-115$.

[17] Rizwan W., Young-Soon K., Amrita M., Soon-II Y., Hyung-Shik S. Formation of ZnO micro-flowers prepared via solution process and their antibacterial activity. Nanoscale Res. Lett., 2010, 5, P. 1675-1681.

[18] Yoon K.Y., Byeon J.H., Park J.H., Hwang J. Susceptibility constants of Escherichia coli and Bacillus subtilis to silver and copper nanoparticles. Sci. Total Environ., 2007, 373, P. 572-575.

[19] Ruparelia J.P., Chatterjee A.K., Duttagupta S.P., Mukherji S. Strain specificity in antimicrobial activity of silver and copper nanoparticles. Acta Biomater, 2008, 4, P. 707-716.

[20] Mazumder A., Davis J., Rangari V., Curry M. Synthesis, characterization, and applications of dendrimer-encapsulated zero-valent Ni nanoparticles as antimicrobial agents. Nanomater, 2013,Article ID 843709, 9 pages.

[21] Khalil A.T., Ovais M., Ullah I., Ali M., Shinwari Z.K., Hassan D., Maaza M. Sageretia thea (Osbeck.) modulated biosynthesis of NiO nanoparticles and their in vitro pharmacognostic, antioxidant and cytotoxic potential. Artif. Cells Blood Substit. Biotechnol., 2018, 46(4), P. 838-852.

[22] Srihasam S., Thyagarajan K., Korivi M., Lebaka V.R., Mallem S.P.R. Phytogenic generation of NiO nanoparticles using Stevia leaf extract and evaluation of their in-vitro antioxidant and antimicrobial properties. Biomolecules, 2020, 10, P. 89.

[23] Helan V., Prince J.J., Al-Dhabi N.A., Arasu M.V., Ayeshamariam A., Madhumitha G., Roopan S.M., Jayachandran M.. Neem leaves mediated preparation of $\mathrm{NiO}$ nanoparticles and its magnetization, coercivity and antibacterial analysis. Results Phys., 2016, 6, P. 712-718.

[24] Abbasi B.A., Iqbal J., Mahmood T., Ahmad R., Kanwal S., Afridi S. Plant-mediated synthesis of nickel oxide nanoparticles (NiO) via Geranium wallichianum: characterization and different biological applications. Mater. Res. Express, 2019, 6, P. 0850a7.

[25] Bhat S.A., Zafar F., Mondal A.H., Kareem A., Mirza A.U., Khan S., Mohammad A., Haq Q.R., Nishat N. Photocatalytic degradation of carcinogenic Congo red dye in aqueous solution, antioxidant activity and bactericidal effect of NiO nanoparticles. J. Iran. Chem. Soc., 2019.

[26] Ahamed M., Alhadlaq H.A., Khan M.M.A., Karuppiah P., Al-Dhabi N.A. Synthesis, characterization, and antimicrobial activity of copper oxide nanoparticles. J. Nanomater., 2014, Article ID 637858, 4 pages.

[27] Hoseinzadeh E., Makhdoumi P., Taha P., Hossini H., Stelling J., Kamal M.A., Ashraf G.M. A review on nano-antimicrobials: Metal nanoparticles, methods and mechanisms. Curr. Drug Metab., 2017, 18(2), P. 120-128.

[28] Djurisic A.B., Leung Y.H., Ng A.M., Xu X.Y., Lee P.K., Degger N., Wu R.S. Toxicity of metal oxide nanoparticles: mechanisms, characterization, and avoiding experimental artefacts. Small, 2015, 11(1), P. 26-44.

[29] Stoimenov P.K., Klinger R.L., Marchin G.L., Klabunde K.J. Metal oxide nanoparticles as bactericidal agents. Langmuir, 2002, 18, P. 66796686.

[30] Rakshit S., Ghosh S., Chall S., Mati S.S., Moulik S.P., Bhattacharya S.C. Controlled synthesis of spin glass nickel oxide nanoparticles and evaluation of their potential antimicrobial activity: A cost effective and eco friendly approach. RSC Adv., 2013, 3, P. 19348-19356.

[31] Helen S.M., Rani H.E. Characterization and antimicrobial study of nickel nanoparticles synthesized from Dioscorea (elephant yam) by green route. Int. J. Sci. Res., 2015, 4, P. 216-219. 
[32] Ayeshamariam A., Sankaracharyulu G.V., Kashif M., Hussain S., Bououdina M., Jayachandran M. Antibacterial activity studies of Ni and SnO2 loaded Chitosan beads. Mater. Sci. Forum, 2015, 833, P. 110-112.

[33] Jesudoss S.K., Vijaya J.J., Clament N., Selvam S., Kombaiah K., Sivachidambaram M., Adinaveen T., Kennedy L.J. Effects of Ba doping on structural, morphological, optical, and photocatalytic properties of self-assembled ZnO nanosphere. Clean Technol. Environ. Policy, 2016, 18, P. 729-741.

[34] Basak G., Das D., Das N. Dual role of acidic diacetate sophorolipid as biostabilizer for ZnO nanoparticles synthesis and biofunctionalizing agent against Salmonella enterica and Candida albicans, J. Microbiol. Biotechnol., 2014, 24, P. 87-96.

[35] Burello E., Worth A.P. A theoretical framework for predicting the oxidative stress potential of oxide nanoparticles. Nanotoxicology, 2011, 5, P. 228-235.

[36] Robison S.H., Cantoni O., Heck J.D., Costa M. Soluble and insoluble nickel compounds induce DNA repair synthesis in cultured mammalian cells. Cancer Lett., 1983, 17(3), P. 273-279.

[37] Oller A.R. Respiratory carcinogenecity assessment of soluble nickel compounds. Environ. Health Perspect., 2002, 110(5), P. 841-844.

[38] Schwerdtle T., Hartwig A. Bioavailability and genotoxicity of soluble and particulate nickel compounds in cultured human lung cells. Materwiss. Werksttech., 2006, 37(6), P. 521-525.

[39] Jan T., Iqbal J., Ismail M., Badshah N., Mansoor Q., Arshad A., Ahkam Q. Synthesis, physical properties and antibacterial activity of metal oxides nanostructures. Mat. Sci. Semicon. Proc., 2014, 21, P. 154-160.

[40] Kalyani R.L., Venkatraju J., Kollu P., Rao N.H., Pammi S.V.N. Low temperature synthesis of various transition metal oxides and their antibacterial activity against multidrug resistance bacterial pathogens. Korean J. Chem. Eng., 2015, 32(5), P. 911-916.

[41] Huh A.J., Kwon Y.J. Nanoantibiotics: A new paradigm for treating infectious diseases using nanomaterials in the antibiotics resistant era. $J$. Control. Release, 2011, 156(2), P. 128-145.

[42] Ling D., Hyeon T. Chemical design of biocompatible iron oxide nanoparticles for medical applications. Small, 2013,9 , P. $1450-1466$.

[43] Mahapatra O., Bhagat M., Gopalakrishnan C., Arunachalam K.D. Ultrafine dispersed CuO nanoparticles and their antibacterial activity. J. Exp. Nanosci., 2008, 3, P. 185-193.

[44] Selvarani M., Prema P. Evaluation of antibacterial efficacy of chemically synthesized copper and zerovalent iron nanoparticles. Asian J. Pharm. Clin. Res., 2013, 6, P. 223-227.

[45] Wang L., Hu C., Shao L. The antimicrobial activity of nanoparticles: Present situation and prospects forthe future. Int. J. Nanomed., 2017, 12, P. 1227.

[46] Kim J.S., Kuk E., Yu K.N., Kim J.H., Park S.J., Lee H.J., Kim S.H., Park Y.K., Park Y.H., Hwang C.Y., Kim Y.K., Lee Y.S., Jeong D.H., Cho M.H. Antimicrobial effects of silver nanoparticles. Nanomed., 2007, 3, P. 95-101.

[47] Sondi I., Salopek-Sondi B. Silver nanoparticles as antimicrobial agent: a case study on E. coli as a model for Gram-negative bacteria. $J$. Colloid. Interf. Sci., 2004, 275, P. 177-182.

[48] Jain P., Pradeep T. Potential of silver nanoparticle-coated polyurethane foam as an antibacterial water filter. Biotechnol. Bioeng., 2005, 90, P. 59-63.

[49] Deravi L.F., Swartz J.D., Wright D.W. The biomimetic synthesis of metal oxide nanomaterials. Wiley, 2010. 